\title{
Triptolide inhibits proliferation, differentiation and induces apoptosis of osteoblastic MC3T3-E1 cells
}

\author{
WEI JI ${ }^{1}$, SHIJIA LIU ${ }^{2}$, XIA ZHAO ${ }^{1}$, YUNKE GUO ${ }^{1}$, SHA XIA $^{3}$, YUEYANG LU ${ }^{4}$, MENYUN YIN $^{3}$ and XIAO XU ${ }^{5}$ \\ ${ }^{1}$ Department of Rheumatology and Immunology; ${ }^{2}$ Laboratory of Clinical Pharmacology, Affiliated Hospital of Nanjing \\ University of Traditional Chinese Medicine, Nanjing, Jiangsu 210029; ${ }^{3}$ Hematology-Oncology Department, Zhenjiang \\ Hospital of Integrated Chinese and Western Medicine, Zhenjiang, Jiangsu 212000; Colleges of ${ }^{4}$ Basic Medical \\ Sciences and ${ }^{5}$ Nursing, Nanjing University of Traditional Chinese Medicine, Nanjing, Jiangsu 210023, P.R. China
}

Received June 8, 2016; Accepted April 10, 2017

DOI: $10.3892 / \mathrm{mmr} .2017 .7568$

\begin{abstract}
Ankylosing spondylitis (AS) is characterized by the formation of bony spurs. Treatment of the resulting ankylosis, excessive bone formation and associated functional impairment, remain the primary therapeutic aims in research regarding this condition. Triptolide is the primary active component of the perennial vine Tripterygium wilfordii Hook. f., and has previously been demonstrated to exert anti-tumor activities including inhibition of cell growth and the induction of apoptosis, however, the effect of triptolide on osteoblasts remains to be elucidated. In the present study, the MC3T3-E1 mouse osteoblast cell line was treated with differing concentrations of triptolide for various intervals. Cell proliferation was detected using the bromodeoxyuridine assay, cell cycle and apoptosis were measured by flow cytometry, nuclear apoptosis was observed by Hoechst staining and associated proteins were determined via western blot analysis. The cells were then further incubated with osteogenic induction medium supplemented with triptolide for 7 or 12 days and the differentiation to osteoblasts was examined by picrosirius staining, observation of alkaline phosphatase activity and a calcium deposition assay. It was demonstrated that treatment with triptolide significantly inhibited osteoblast proliferation and induced cell cycle arrest and apoptosis of the osteoblasts. Furthermore, treatment with triptolide reduced collagen formation, alkaline phosphatase activity and calcium deposition. The present study demonstrated an inhibitory effect of triptolide on osteoblast proliferation and differentiation, and therefore suggests a potential therapeutic agent for the treatment of AS in the future.
\end{abstract}

Correspondence to: Dr Wei Ji, Department of Rheumatology and Immunology, Affiliated Hospital of Nanjing University of Traditional Chinese Medicine, 155 Hanzhong Road, Nanjing, Jiangsu 210029, P.R. China

E-mail:weiweiji1103@163.com

Key words: ankylosing spondylitis, triptolide, osteoblast, proliferation, differentiation, apoptosis

\section{Introduction}

Ankylosing spondylitis (AS) is a chronic inflammatory arthritis which primarily affects the sacroiliac joints and spine. It is characterized by the formation of bony spurs leading to ankyloses, and the associated functional impairment ultimately leads to disability (1). AS is a frequently occurring condition in young men $\sim 26$ years of age, with a prevalence of $0.15-0.8 \%$ in the ordinary population (2). Conventional medical treatment, including disease-modifying anti-rheumatic drugs, non-steroidal anti-inflammatory drugs and corticosteroids do not adequately treat or control the symptoms associated with AS in the majority of patients (3). The etiology and pathogenesis of AS remains to be fully elucidated, therefore, control of the excessive bone formation remains the primary aim in the treatment of AS (4).

The perennial vine Tripterygium wilfordii Hook. f. is a traditional Chinese herb with verified anti-inflammatory, immunosuppressive and anti-proliferative properties $(5,6)$. The primary active component is triptolide, which is clinically used in the treatment of rheumatoid arthritis, glomerulonephritis and various other autoimmune diseases (7-9). It has previously been demonstrated that triptolide additionally exhibits anti-tumor activities due to the observed inhibition of cell growth and induction of apoptosis (10-12). However, to the best of our knowledge, there is no available information demonstrating if triptolide exhibits a role in the regulation of osteoblast biological activity.

In the present study, a mouse osteoblast cell line was employed to investigate the effect of triptolide on the proliferation, differentiation and apoptosis of osteoblasts. The present study determined that treatment with triptolide may inhibit proliferation, induce cell cycle arrest and apoptosis of the MC3T3-E1 mouse osteoblast cells in a dose-dependent manner. Additionally, the osteogenic differentiation of these osteoblast cells was suppressed by triptolide. These results may be of important clinical significance in the control of AS.

\section{Materials and methods}

Cell culture and osteogenic induction. The MC3T3-E1 mouse osteoblast cell line was purchased from Type Culture 
Collection Center of Chinese Academy of Sciences (Shanghai, China). Cells were cultured in Minimum Essential Medium (MEM)- $\alpha$ (Gibco; Thermo Fisher Scientific, Inc., Waltham, MA, USA) supplemented with $10 \%$ fetal bovine serum (FBS; Hyclone; GE Healthcare, Logan, UT, USA) at $37^{\circ} \mathrm{C}$ in an environment containing $5 \% \mathrm{CO}_{2}$. For osteogenic induction, the culture medium was altered to MEM- $\alpha$ containing $5 \mathrm{mM} \beta$-glycerophosphate (BioSharp, Hefei, China) and $50 \mu \mathrm{g} / \mathrm{ml}$ vitamin C (Sigma-Aldrich; Merck KGaA, Darmstadt, Germany).

Bromodeoxyuridine (BrdU) assay. Cell viability was detected by BrdU ELISA kit (cat. no. CEL-BRDU, Mai Biological Technology Co., Ltd., Changsha, China) according to the manufacturer's protocol. Briefly, cells were seeded in 96-well plates with MEM- $\alpha$ for $24 \mathrm{~h}$, then supplemented with 0, 2.8, 7 or $14 \mathrm{nM}$ triptolide (Sigma-Aldrich; Merck KGaA). Following incubation for 24,48 , or $72 \mathrm{~h}, 10 \mu \mathrm{l}$ BrdU labeling buffer was added, and incubated for a further $2 \mathrm{~h}$ at $37^{\circ} \mathrm{C}$. Next, the cells were fixed and denaturalized with $200 \mu 1$ FixDenat solution and incubated with $100 \mu \mathrm{l}$ peroxidase conjugated anti-BrdU-monoclonal antibody at room temperature for $90 \mathrm{~min}$. Then, $100 \mu \mathrm{l}$ substrate solution was added and the color was developed for $20 \mathrm{~min}$. Finally, the reaction was stopped with the addition of $25 \mu \mathrm{l}$ stop solution and absorbance was subsequently measured at a wavelength of $450 \mathrm{~nm}$.

Flow cytometry. Cells were seeded in 6-well plates at a density of $1 \times 10^{5}$ cells/well, and allowed to grow to $90 \%$ confluence. Then, the cells were treated with $0,2.8,7$ or $14 \mathrm{nM}$ triptolide for $72 \mathrm{~h}$. For cell cycle analysis, the cells were fixed with $70 \%$ alcohol at $4^{\circ} \mathrm{C}$ for $2 \mathrm{~h}$, then incubated with $25 \mu \mathrm{l}$ propidium iodide (PI) staining solution (Beyotime Institute of Biotechnology, Haimen, China) and $10 \mu \mathrm{l}$ RNase A for $30 \mathrm{~min}$ at $37^{\circ} \mathrm{C}$ in the dark. Following this, the cell cycle progression was quantified using a flow cytometer (BD Accuri C6; BD Biosciences, Franklin Lakes, NJ, USA). Cell apoptosis was detected using the Annexin-V fluorescein isothiocyanate (FITC) and PI double staining kit (Nanjing KeyGen Biotech Co., Ltd., Nanjing, China) as per the manufacturer's protocol. The cells were stained with $5 \mu$ l Annexin V-FITC and $5 \mu \mathrm{l}$ PI for $15 \mathrm{~min}$ in dark, then subjected to BD Accuri C6 flow cytometer. Cell cycle and apoptosis status were analyzed by Accuri CFlow Plus version 1.0.1727 (BD Biosciences).

Hoechst staining. Nuclear apoptosis was detected using a Hoechst staining kit (Beyotime Institute of Biotechnology) according to the manufacturer's protocol. Following treatment with different concentrations of triptolide, cells were fixed with $500 \mu \mathrm{l}$ fixative at $4^{\circ} \mathrm{C}$ overnight. The cells were stained with $2 \mu \mathrm{g} / \mathrm{ml}$ Hoechst 33258 staining solution at $37^{\circ} \mathrm{C}$ for $30 \mathrm{~min}$. The stained cells were observed under a fluorescent microscope (BX53; Olympus Corporation, Tokyo, Japan).

Western blotting. Cells were lysed using a radioimmunoprecipitation buffer (Beyotime Institute of Biotechnology) supplemented with $10 \%$ phenylmethane sulfonyl fluoride (Beyotime Institute of Biotechnology). The concentration of extracted proteins was determined by a

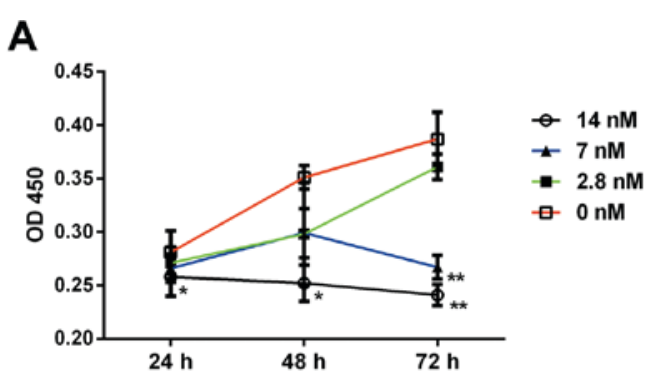

B
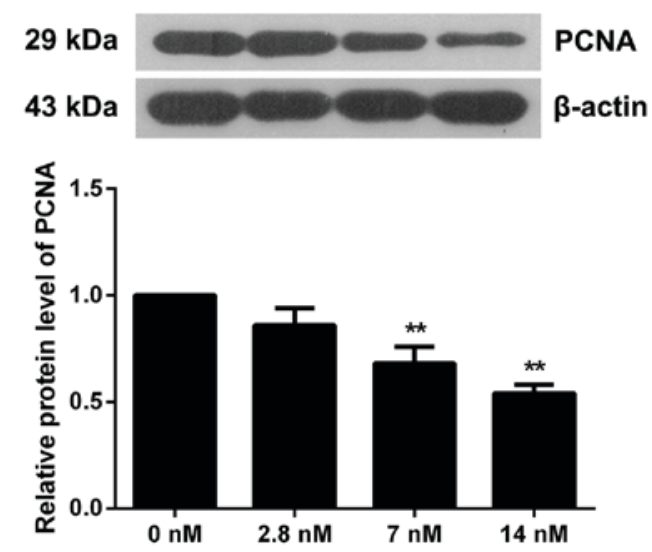

Figure 1. Triptolide inhibits proliferation of MC3T3-E1 cells. (A) Cell proliferation was detected by the Bromodeoxyuridine assay; $n=6$. (B) The expression of PCNA was detected by western blotting at $72 \mathrm{~h}$ of triptolide treatment; $n=3$, representative protein bands are presented. Data are expressed as the mean \pm standard deviation. ${ }^{*} \mathrm{P}<0.05 ;{ }^{* *} \mathrm{P}<0.01$ vs. $0 \mathrm{nM}$ triptolide treatment group. OD, optical density; PCNA, proliferating cell nuclear antigen.

conventional bicinchoninic acid method (Beyotime Institute of Biotechnology). An equal amount of $40 \mu \mathrm{g}$ protein was electrophoresed on 10 or $13 \%$ SDS-PAGE. The proteins were electrotransferred to a polyvinylidene fluoride membrane (EMD Millipore, Billerica, MA, USA). Following blocking with $5 \%(\mathrm{M} / \mathrm{V})$ skimmed milk, the membrane was immunoblotted with primary antibodies against proliferating cell nuclear antigen (PCNA; 1:500; cat. no. bs-2006R; BIOSS, Beijing, China); cyclin D1, (1:400; cat. no. BM0771); cyclin E, (1:400; cat. no BA0774); B cell lymphoma (Bcl)-2, (1:400; cat. no. BA0412); Bcl-2 associated X protein (Bax), (cat. no. BA0315; 1:400) all purchased from Boster Biological Technology, Pleasanton, CA, USA) and cleaved-caspase 3, (cat. no. ab2302; 1:1,000; Abcam, Cambridge, MA, USA) at $4^{\circ} \mathrm{C}$ overnight. Following this, the membrane was incubated with horseradish peroxidase-conjugated goat anti-rabbit (1:5,000; cat. no. WLA023; Wanleibio, Shenyang, China) or goat anti-mice antibody (1:5,000, cat. no. WLA024; Wanleibio) at $37^{\circ} \mathrm{C}$ for $45 \mathrm{~min}$. The specific protein bands were detected by an enhanced chemiluminescence reagent (7Sea biotech Co., Ltd., Shanghai, China) and quantified by Gel-Pro Analyzer Version 3.0 (Media Cybernetics, Inc., Rockville, MD, USA). $\beta$-actin served as an internal control.

Picrosirius staining. Cells were cultured in osteogenic induction medium with various concentrations of triptolide at $37^{\circ} \mathrm{C}$ in an environment containing 5\% $\mathrm{CO}_{2}$ for 7 days. Following fixing with $1 \mathrm{ml}$ Bouin's solution (Sigma-Aldrich; Merck $\mathrm{KGaA}$ ) at room temperature for $1 \mathrm{~h}$, the cells were stained 
A
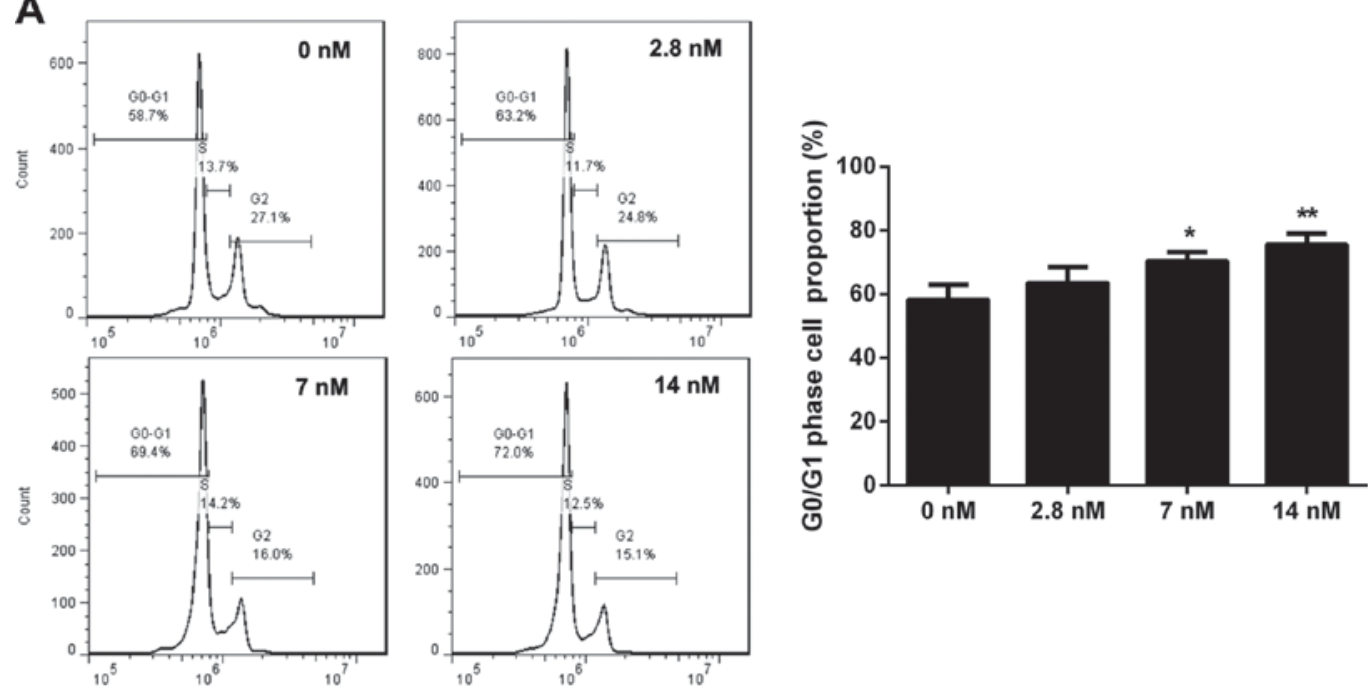

B

C
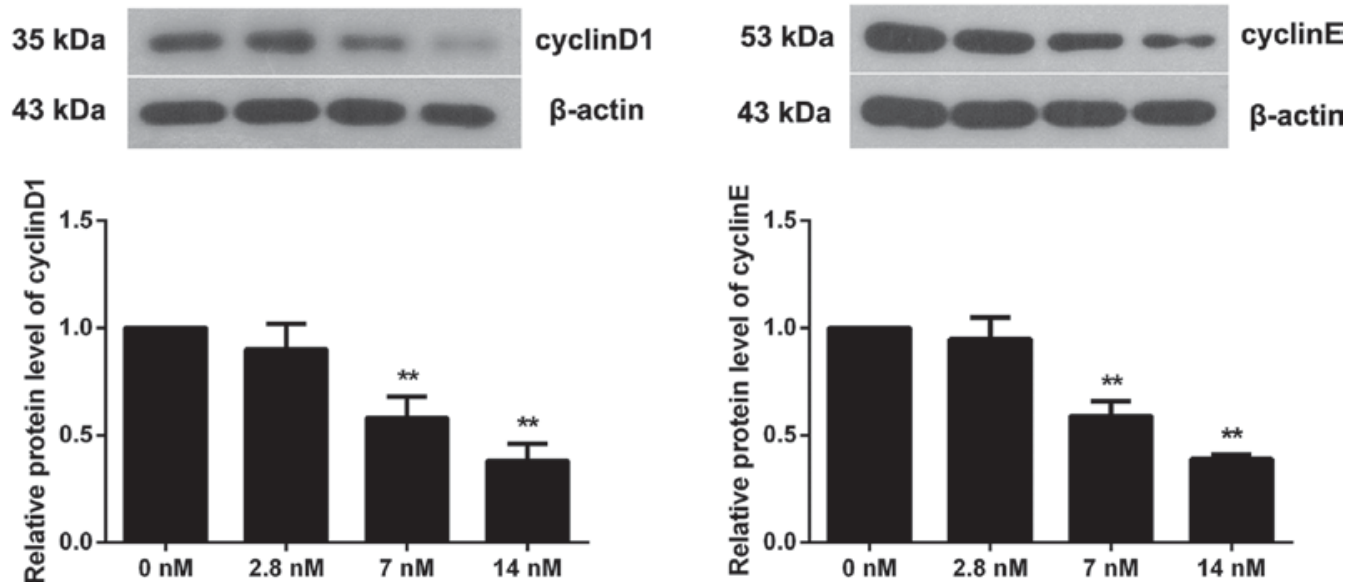

Figure 2. Triptolide induces cell cycle arrest of MC3T3-E1 cells. (A) Cells were incubated with different concentrations of triptolide for 72 h. Cell cycle was measured by flow cytometry; $\mathrm{n}=3$. The protein expression levels of (B) cyclin D1 and (C) cyclin E were detected by western blotting; $\mathrm{n}=3$. Data are expressed as the mean \pm standard deviation. ${ }^{*} \mathrm{P}<0.05 ;{ }^{* *} \mathrm{P}<0.01$ vs. $0 \mathrm{nM}$ triptolide treatment group.

with $1 \%$ Sirius red in saturated picric acid for $1 \mathrm{~h}$. The cells were then washed and observed under an optical microscope (DP73; Olympus Corporation).

Measurement of alkaline phosphatase activity and calcium deposition. MC3T3-E1 cells were cultured in osteogenic induction medium supplemented with various concentrations of triptolide for 12 days. The cells were then collected and lysed by repeated freezing and thawing with liquid nitrogen. Proteins were quantified using a conventional bicinchoninic acid method and diluted to $1 \mathrm{mg} / \mathrm{ml}$. Alkaline phosphatase activity and calcium deposition were measured using the commercial kits following the manufacturer's instructions. The AKP/ALP detection kit was purchased from Nanjing Jiancheng Bioengineering Institute (cat. no. A059-1, Nanjing, China) and the calcium colorimetric assay kit was purchased from Sigma-Aldrich (cat. no. MAK022, Merck KGaA, Darmstadt, Germany). Absorbance value was detected at $520 \mathrm{~nm}$ for ALP and at $575 \mathrm{~nm}$ for calcium ions were measured using a microplate spectrophotometer and its assorted software Gen5 version 2.0 (ELx-800, Biotek Instruments, Winooski, VT, USA).
Statistical analysis. All data are presented as the mean \pm standard deviation. Statistical analysis was performed using SPSS software, version 16.0 (SPSS, Inc., Chicago, IL, USA) and data were evaluated by analysis of variance, followed by the Bonferroni test. $\mathrm{P}<0.05$ was considered to indicate a statistically significant difference.

\section{Results}

Triptolide inhibits MC3T3-E1 cell proliferation. MC3T3-E1 cells were treated with increasing concentrations of triptolide $(0,2.8,7$ or $14 \mathrm{nM})$ for 24,48 or $72 \mathrm{~h}$ and the effect of triptolide on the cells was tested using the BrdU-based viability assay. As presented in Fig. 1A, $2.8 \mathrm{nM}$ triptolide did not affect the cell viability, $7 \mathrm{nM}$ triptolide significantly inhibited cell viability at $72 \mathrm{~h}(\mathrm{P}<0.01)$, and cells exposed to $14 \mathrm{nM}$ triptolide exhibited a marked decrease in proliferation at 24, 48 and $72 \mathrm{~h}$ when compared with non-treated cells $(\mathrm{P}<0.05)$. Therefore, triptolide inhibited MC3T3-E1 cell viability in a dose and time-dependent manner. Furthermore, the expression of PCNA was detected by western blotting and it was observed that MC3T3-E1 cells exposed to 7 or $14 \mathrm{nM}$ triptolide for $72 \mathrm{~h}$ 

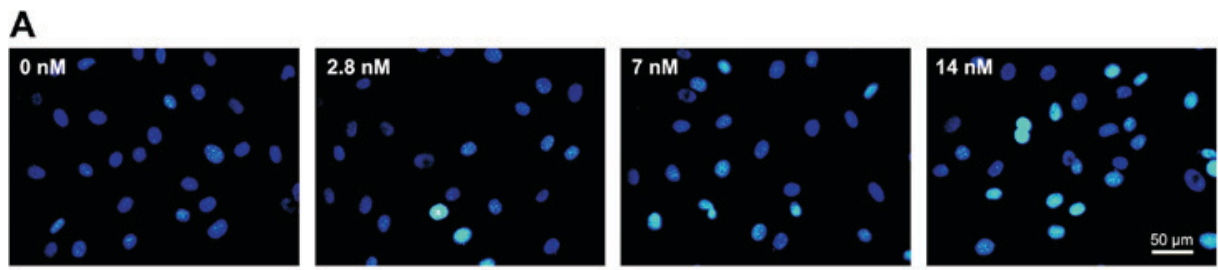

B
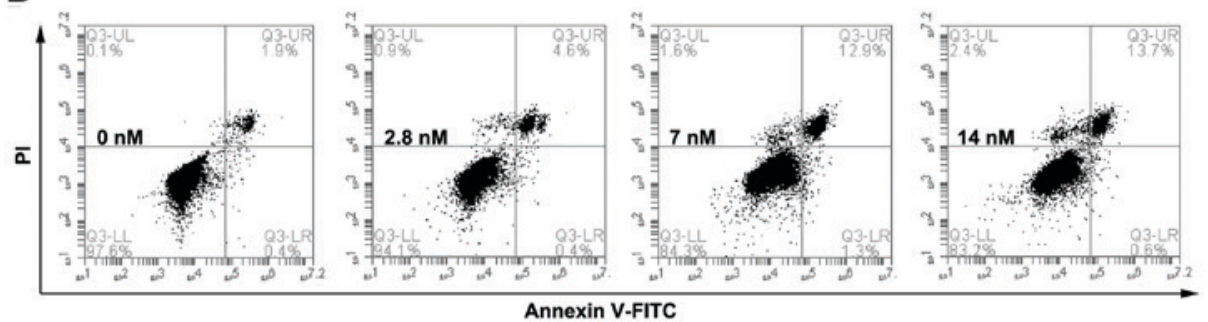

C

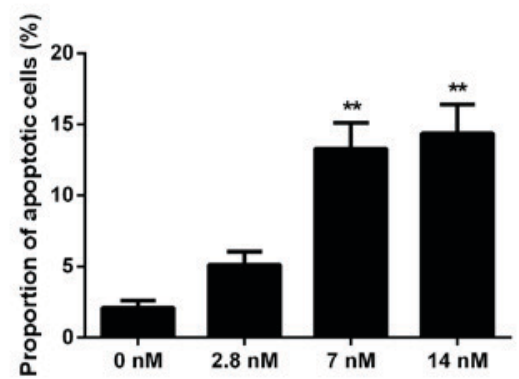

E
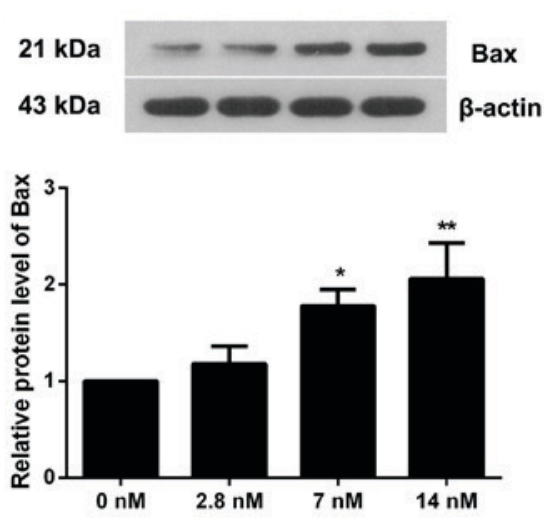

D
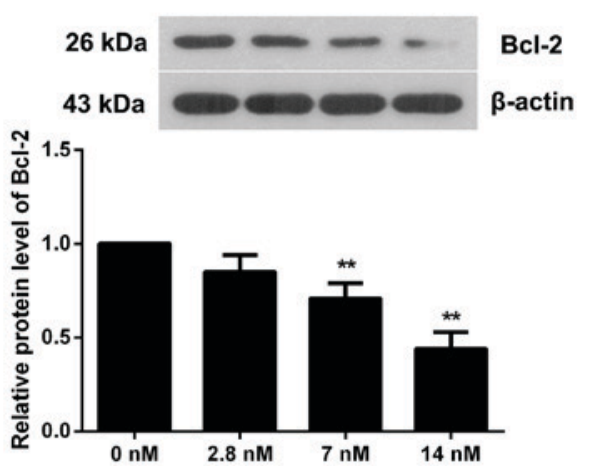

$\mathbf{F}$

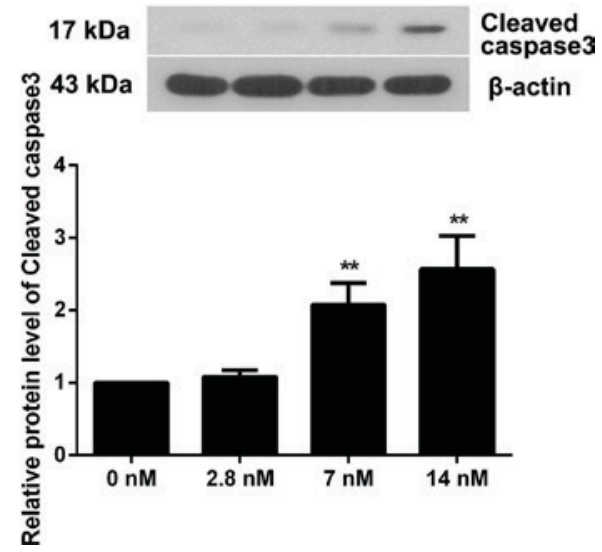

Figure 3. Triptolide induces apoptosis of MC3T3-E1 cells. (A) Cells were incubated with increasing concentrations of triptolide for $72 \mathrm{~h}$ and apoptotic nuclei were observed via Hoechst staining. The proportion of apoptotic cells was detected by flow cytometry and presented as (B) a representative image and (C) quantification of results. The expression of (D) Bcl-2, (E) Bax and (F) cleaved caspase 3 was determined by western blotting. All experiments were repeated in triplicate. Data are presented as the mean \pm standard deviation. ${ }^{*} \mathrm{P}<0.05 ;{ }^{* *} \mathrm{P}<0.01$ vs. $0 \mathrm{nM}$ triptolide treatment group. Bcl-2, B cell lymphoma; Bax, Bcl-2 associated X protein.

exhibited significantly inhibited PCNA levels $(\mathrm{P}<0.01)$. These results further indicated the suppressive effect of triptolide on osteoblast proliferation (Fig. 1B).

Triptolide induces cell cycle arrest of MC3T3-E1 cells. To investigate if triptolide affects the MC3T3-E1 cell cycle, flow cytometry was performed when cells were incubated with triptolide for $72 \mathrm{~h}$. As presented in Fig. 2A, the proportion of cells in the G0/G1 phase in the 7 or $14 \mathrm{nM}$ triptolide treatment groups was significantly increased $(\mathrm{P}<0.05)$, indicating a cell cycle arrest induced by triptolide. The expression of two pivotal proteins in the regulation of the cell cycle, cyclin D1 and cyclin E, was additionally determined (Fig. 2B and C). The results demonstrated that 7 or $14 \mathrm{nM}$ triptolide significantly reduced the level of cyclin D1 and cyclin E $(\mathrm{P}<0.01)$. Therefore, tripolide may induce cell cycle arrest at the G0/G1 phase via inhibition of cyclin D1 and cyclin E expression.

Triptolide induces apoptosis of MC3T3-E1 cells. Hoechst staining was used to evaluate the apoptotic status of triptolide treated cells. As presented in Fig. 3A, blue apoptotic nuclei were observed in $2.8 \mathrm{nM}$ triptolide treated cells, and this was 

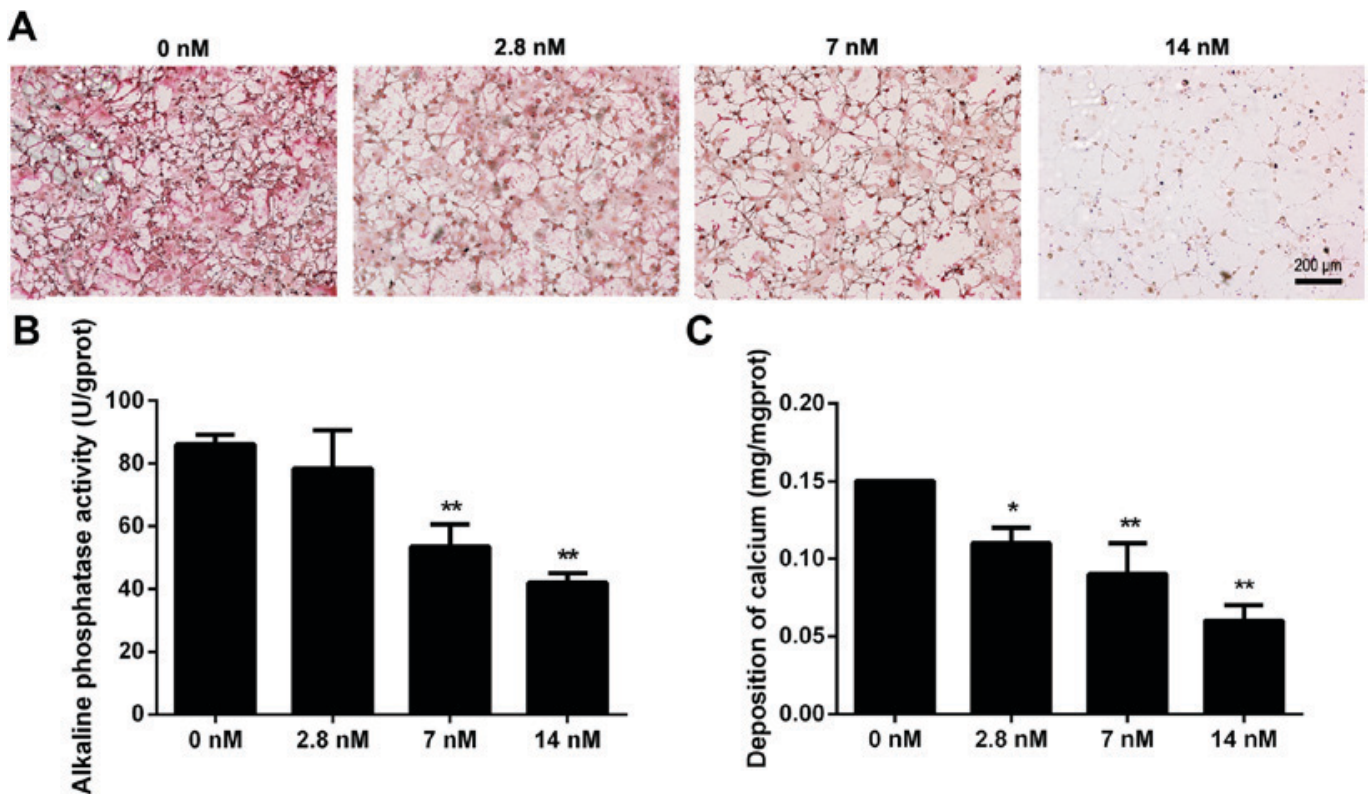

Figure 4. Triptolide suppresses differentiation of MC3T3-E1 cells. Cells were incubated in osteogenic induction medium supplemented with different concentrations of triptolide. (A) Collagen formation at day 7 was examined by picrosirius staining. (B) Alkaline phosphatase activity and (C) calcium deposition were detected at day 12. Experiments were repeated at least three times. Data are expressed as the mean \pm standard deviation. ${ }^{*} \mathrm{P}<0.05,{ }^{* *} \mathrm{P}<0.01$ vs. $0 \mathrm{nM}$ triptolide treatment group.

elevated with the increased triptolide concentration. Flow cytometry additionally demonstrated that the proportion of apoptotic cells was increased in triptolide treated cells, particularly in the 7 and $14 \mathrm{nM}$ triptolide treated groups (Fig. 3B and $\mathrm{C} ; \mathrm{P}<0.01$ ). Measurement of apoptosis-associated proteins demonstrated that the level of $\mathrm{Bcl}-2$ was decreased as the triptolide concentration increased (Fig. 3D). Conversely, the protein levels of Bax and Cleaved caspase 3 were upregulated (Fig. 3E and F).

Triptolide suppresses differentiation and mineralization of MC3T3-El cells. To examine the effect of triptolide on osteoblast differentiation, MC3T3-E1 cells were cultured in osteogenic induction medium with different concentrations of triptolide. The collagen formation was observed by picrosirius staining at day 7 and the results demonstrated that the collagen fibers were decreased with the increased triptolide concentrations (Fig. 4A). The activity of alkaline phosphatase is a marker of osteoblastic differentiation, and the level of activity was subsequently determined at day 12. It was demonstrated that 7 and $14 \mathrm{nM}$ triptolide significantly reduced the alkaline phosphatase activity (Fig. 4B; $\mathrm{P}<0.01$ ). Furthermore, calcium deposition was measured to investigate the mineralized matrix formation in triptolide treated cells, as demonstrated in Fig. 4C. The cells exposed to $2.8,7$ or $14 \mathrm{nM}$ triptolide exhibited a significantly decreased level of calcium deposition, when compared with the control group $(\mathrm{P}<0.05)$. Triptolide therefore suppressed differentiation and mineralization of MC3T3-E1 cells.

\section{Discussion}

The anti-inflammatory and anti-neoplastic properties of triptolide have been extensively reported (13-16), however, the effect on the regulation of biological activities in osteoblasts remains to be elucidated. In the present study, mouse osteoblast
MC3T3-E1 cells were treated with increasing concentrations of triptolide at different time intervals, and it was demonstrated that triptolide inhibited cell proliferation in a dose and time-dependent manner. Triptolide additionally induced cell cycle arrest and apoptosis of MC3T3-E1 cells. Treatment with triptolide resulted in delayed collagen formation, decreased alkaline phosphatase activity and reduced calcium deposition. The findings therefore demonstrated the suppressive effect of triptolide on osteoblast proliferation and bone formation.

The growth inhibition effect of triptolide has been demonstrated in a variety of solid tumor types, in vivo and in vitro $(17,18)$. It was revealed that triptolide inhibited cell proliferation in a dose and time-dependent manner in mouse osteoblast MC3T3-E1 cells. PCNA is a highly conservative nuclear protein of DNA polymerase- $\Delta$, and is considered to be a useful marker to assess cell proliferation and progression $(19,20)$. In the present study, 7 and $14 \mathrm{nM}$ triptolide significantly reduced the expression of PCNA in MC3T3-E1 cells and further proved the inhibitory effect of triptolide on cell proliferation. These results are in accordance with previous studies on tumor (21) and T-lymphocyte cells (22).

The cell cycle is regulated by a range of components including cyclin-proteins, cyclin-dependent kinases (CDK) and various other factors. The loss of function of these regulators may result in cell cycle disorder and uncontrolled cell proliferation. During the cell cycle, cyclin D1 combines with CDK4 or CDK6 and cyclin E combines with CDK2. The cyclin and CDK complexes phosphorylate $\mathrm{Rb}$, release E2F and thereby activate the transition from the G1 to the $\mathrm{S}$ phase (23-25). It has previously been demonstrated that triptolide decreases proliferation, induces G0/G1 cycle arrest and suppresses the expression of cyclin-proteins in multiple myeloma cells (26), malignant glioma cells (27) and colon-rectal cancer cells $(28,29)$. Consistent with previous studies, the present study demonstrated that triptolide triggered 
G0/G1 arrest and inhibited the expression of cyclin D1 and cyclin E in osteoblasts.

Cell cycle arrest and apoptosis are highly associated events and disruption of the cell cycle induces apoptosis (30). Bcl-2 family proteins, including anti-apoptotic Bcl-2, Bcl- $\mathrm{X}_{\mathrm{L}}$ and pro-apoptotic Bax, are key regulators in mitochondria-dependent apoptosis (31), and caspase 3 is the final executor in this pathway (32). Li et al (33) reported in human renal cell carcinoma cells that triptolide increases Bax expression, reduces Bcl-2 level, increased caspase 3 activity, and induces cell apoptosis in a dose- dependent manner. The results of the present study are in accordance with the reports on human renal cell carcinoma cells, and triptolide induced the apoptosis of MC3T3-E1 cells via suppression of $\mathrm{Bcl}-2$ and promotion of Bax.

Osteogenesis is a well-coordinated physiological process including extracellular matrix production, secretion, and matrix mineralization (34). To verify the effect of triptolide on osteogenesis, MC3T3-E1 cells were incubated in osteogenesis induction medium with different concentrations of triptolide. The results demonstrated that triptolide blocked collagen formation, suppressed alkaline phosphatase activity and reduced calcium deposition, suggesting an inhibitory effect of triptolide on osteoblast differentiation. However, Huang et al (35) and Park (36) demonstrated that triptolide inhibits osteoclastogenesis and bone resorption, respectively. Therefore, triptolide may exhibit a bidirectional role in bone regulation, and further studies are required in order to fully elucidate the underlying mechanisms.

In conclusion, the data from the present study demonstrated that triptolide inhibited proliferation and induced cell cycle arrest and apoptosis of osteoblasts. In addition, triptolide was identified as a potent suppressor of osteoblast differentiation and mineralization. These results verify the inhibitory effect of triptolide in bone formation and suggest a potential treatment strategy for AS in the future.

\section{Acknowledgements}

The present study was supported by the High-Level Talent Project of Jiangsu Province Hospital of Traditional Chinese Medicine (grant no. y2014rc08), the Natural Science Foundation of Jiangsu Province (grant no. BK20151602) and the National Natural Science Foundation of China (grant no. 81403174).

\section{References}

1. Braun J and Sieper J: The sacroiliac joint in the spondyloarthropathies. Curr Opin Rheumatol 8: 275-287, 1996.

2. Reveille JD and Brown MA: Epidemiology of ankylosing spondylitis: IGAS 2009. J Rheumatol 37: 2624-2625, 2010.

3. Toussirot E and Wendling D: Current guidelines for the drug treatment of ankylosing spondylitis. Drugs 56: 225-240, 1998.

4. Schett G and Rudwaleit M: Can we stop progression of ankylosing spondylitis? Best Pract Res Clin Rheumatol 24: 363-371, 2010.

5. Wang J, Wang A, Zeng $\mathrm{H}$, Liu L, Jiang W, Zhu Y and Xu Y: Effect of triptolide on T-cell receptor beta variable gene mRNA expression in rats with collagen-induced arthritis. Anat Rec (Hoboken) 295: 922-927, 2012.

6. Xue M, Jiang ZZ, Liu JP, Zhang LY, Wang T, Wang H, Liu L and Zhou ZX: Comparative study on the anti-inflammatory and immune suppressive effect of Wilforlide A. Fitoterapia 81: $1109-1112,2010$
7. Shui G, Wan Y, Jiang C, Zhang H, Chen P, Wang C and Yao J: Progress in Tripterygium wilfordiiand its bioactive components in the field of pharmacodynamics and pharmacology. Zhongguo Zhong Yao Za Zhi 35: 515-520, 2010.

8. Brinker AM, Ma J, Lipsky PE and Raskin I: Medicinal chemistry and pharmacology of genus Tripterygium (Celastraceae). Phytochemistry 68: 732-766, 2007 (In Chinese).

9. Liu C, Zhang Y, Kong X, Zhu L, Pang J, Xu Y, Chen W, Zhan H, $\mathrm{Lu} \mathrm{A}$ and Lin N: Triptolide prevents bone destruction in the collagen-induced arthritis model of rheumatoid arthritis by targeting RANKL/RANK/OPG signal pathway. Evid Based Complement Alternat Med 2013: 626038, 2013.

10. Jiang QW, Cheng KJ, Mei XL, Qiu JG, Zhang WJ, Xue YQ, Qin WM, Yang Y, Zheng DW, Chen Y, et al: Synergistic anticancer effects of triptolide and celastrol, two main compounds from thunder god vine. Oncotarget 6: 32790-32804, 2015.

11. Jao HY, Yu FS, Yu CS, Chang SJ, Liu KC, Liao CL, Ji BC, Bau DT and Chung JG: Suppression of the migration and invasion is mediated by triptolide in B16F10 mouse melanoma cells through the NF-kappaB-dependent pathway. Environ Toxicol: Sep 29, 2015 (Epub ahead of print).

12. Jiang N, Dong XP, Zhang SL, You QY, Jiang XT and Zhao XG: Triptolide reverses the Taxol resistance of lung adenocarcinoma by inhibiting the NF- $\mathrm{KB}$ signaling pathway and the expression of NF- $\kappa$ B-regulated drug-resistant genes. Mol Med Rep 13: 153-159, 2016.

13. Zhou GX, Ding XL, Huang JF, Zhang H, Wu SB, Cheng JP and Wei Q: Apoptosis of human pancreatic cancer cells induced by Triptolide. World J Gastroenterol 14: 1504-1509, 2008.

14. Pan J: RNA polymerase-an important molecular target of triptolide in cancer cells. Cancer Lett 292: 149-152, 2010.

15. Qiu D and Kao PN: Immunosuppressive and anti-inflammatory mechanisms of triptolide, the principal active diterpenoid from the Chinese medicinal herb Tripterygium wilfordii Hook. f. Drugs R D 4: 1-18, 2003.

16. Matta R, Wang X, Ge H, Ray W, Nelin LD and Liu Y: Triptolide induces anti-inflammatory cellular responses. Am J Transl Res 1: 267-282, 2009

17. Chen L, Liu Q, Huang Z, Wu F, Li Z, Chen X and Lin T: Tripchlorolide induces cell death in lung cancer cells by autophagy. Int J Oncol 40: 1066-1070, 2012.

18. Westfall SD, Nilsson EE and Skinner MK: Role of triptolide as an adjunct chemotherapy for ovarian cancer. Chemotherapy 54: 67-76, 2008.

19. Bodduluru LN, Kasala ER, Madhana RM, Barua CC, Hussain MI, Haloi P and Borah P: Naringenin ameliorates inflammation and cell proliferation in benzo(a)pyrene induced pulmonary carcinogenesis by modulating CYP1A1, NFKB and PCNA expression. Int Immunopharmacol 30: 102-110, 2016.

20. Ben-Izhak O, Bar-Chana M, Sussman L, Dobiner V, Sandbank J, Cagnano M, Cohen H and Sabo E: Ki67 antigen and PCNA proliferation markers predict survival in anorectal malignant melanoma. Histopathology 41: 519-525, 2002.

21. Yang S, Chen J, Guo Z, Xu XM, Wang L, Pei XF, Yang J, Underhill CB and Zhang L: Triptolide inhibits the growth and metastasis of solid tumors. Mol Cancer Ther 2: 65-72, 2003.

22. Yang SX, Xie SS, Gao HL, Ma DL and Long ZZ: Triptolide suppresses T-lymphocyte proliferation by inhibiting interleukin-2 receptor expression, but spares interleukin-2 production and mRNA expression. Int J Immunopharmacol 16: 895-904, 1994.

23. Sherr CJ: G1 phase progression: Cycling on cue. Cell 79: 551-555, 1994.

24. Sherr CJ: Growth factor-regulated G1 cyclins. Stem Cells 12 (Suppl 1): S47-S57, 1994.

25. Sherr CJ, Kato J, Quelle DE, Matsuoka M and Roussel MF: D-type cyclins and their cyclin-dependent kinases: G1 phase integrators of the mitogenic response. Cold Spring Harb Symp Quant Biol 59: 11-19, 1994.

26. Zhao F, Chen Y, Li R, Liu Y, Wen L and Zhang C: Triptolide alters histone $\mathrm{H} 3 \mathrm{~K} 9$ and $\mathrm{H} 3 \mathrm{~K} 27$ methylation state and induces G0/G1 arrest and caspase-dependent apoptosis in multiple myeloma in vitro. Toxicology 267: 70-79, 2010.

27. Zhang H, Zhu W, Su X, Wu S, Lin Y, Li J, Wang Y, Chen J, Zhou Y, Qiu P, et al: Triptolide inhibits proliferation and invasion of malignant glioma cells. J Neurooncol 109: 53-62, 2012.

28. Liu J, Shen M, Yue Z, Yang Z, Wang M, Li C, Xin C, Wang Y, Mei Q and Wang Z: Triptolide inhibits colon-rectal cancer cells proliferation by induction of G1 phase arrest through upregulation of p21. Phytomedicine 19: 756-762, 2012. 
29. Oliveira AR, Beyer G, Chugh R, Skube SJ, Majumder K Banerjee S, Sangwan V, Li L, Dawra RK, Subramanian S, et al: Triptolide abrogates growth of colon cancer and induces cell cycle arrest by inhibiting transcriptional activation of E2F. Lab Invest 95: 648-659, 2015.

30. Pucci B, Kasten M and Giordano A: Cell cycle and apoptosis. Neoplasia 2: 291-299, 2000.

31. Martinou JC and Youle RJ: Mitochondria in apoptosis: Bcl-2 family members and mitochondrial dynamics. Dev cell 21: 92-101, 2011.

32. Donovan M and Cotter TG: Control of mitochondrial integrity by Bcl-2 family members and caspase-independent cell death. Biochim Biophys Acta 1644: 133-147, 2004.

33. Li J, Zhu W, Leng T, Shu M, Huang Y, Xu D, Qiu P, Su X and Yan G: Triptolide-induced cell cycle arrest and apoptosis in human renal cell carcinoma cells. Oncol Rep 25: 979-987, 2011.
34. Owen TA, Aronow M, Shalhoub V, Barone LM, Wilming L, Tassinari MS, Kennedy MB, Pockwinse S, Lian JB and Stein GS: Progressive development of the rat osteoblast phenotype in vitro: Reciprocal relationships in expression of genes associated with osteoblast proliferation and differentiation during formation of the bone extracellular matrix. J Cell Physiol 143: 420-430, 1990.

35. Huang J, Zhou L, Wu H, Pavlos N, Chim SM, Liu Q, Zhao J, Xue W, Tan RX, Ye J, et al: Triptolide inhibits osteoclast formation, bone resorption, RANKL-mediated $\mathrm{NF}_{-} \kappa \mathrm{B}$ activation and titanium particle-induced osteolysis in a mouse model. Mol Cell Endocrinol 399: 346-353, 2015.

36. Park B: Triptolide, a diterpene, inhibits osteoclastogenesis, induced by RANKL signaling and human cancer cells. Biochimie 105: 129-136, 2014. 